\title{
Farklı Basamaklardaki Sağlık Kuruluşlarına Başvuran Ailelerin Çocukları ile Oyun Oynama, Kitap Okuma ve Ekran İzletme Alışkanlıklarının Değerlendirilmesi
}

\author{
Evaluating The Habits of Playing, Reading With Child And Screen \\ Viewing of Families Applying to Health Centers at Different Levels \\ Tuba ÇELEN YOLDAŞ, Elif ÖZMERT
}

Hacettepe Üniversitesi Tıp Fakültesi, Çocuk Sağlığı ve Hastalıkları Anabilim Dalı, Gelişimsel Pediatri Anabilim Dalı, Ankara, Turkiye

\begin{abstract}
öz
Amaç: Sağllk sistemi bütün çocuklara sosyoekonomik durumdan bağımsız olarak erişebilmenin tek yoludur ve çocuk sağlığı hizmeti verenler ailelere ulaşabilmek için anahtar konumdadırlar. Günümüzde oyun, okuma ve ekran izleme alışkanlıkları çocukların gelişimini etkileyen en temel konular olarak bilinmektedir ancak bu alışkanlıklara dair ülkemizde yeterli veri yoktur. Çalışmamızda ebeveynlerin çocuklarılla oyun oynama, kitap okuma ve ekran izletme alışkanlıklarını değerlendirmeyi ve bu alışkanlıkların sağlık sisteminin her düzeyinde nasıl ayrışı̆̆ını araştırmayı amaçladık.
\end{abstract}

Gereç ve Yöntemler: Gelişimsel Pediatri Bilim Dalı tarafından Ocak 2015- Ocak 2016 tarihleri arasında yürütülen bu çalışmada 1-6 yaş arasındaki çocuklarına yönelik tıbbi bir hizmet için başvuran toplam 451 ebeveyne (156'sı üçüncü basamak sağlik merkezi-Üniversite Hastanesi-ÜH, 148'i ikinci basamak sağlik merkezi-Devlet Hastanesi-DH ve 147'si birinci basamak sağllk merkezi - Aile Sağlığı Merkezi-ASM) bir anket verildi. Bu ankette sosyodemografik bilgilerin yanında ebeveynlerin çocukları ile oyun oynama, çocuklarına kitap okuma ve çocukların televizyon izleme alıșkanlıkları değerlendirildi.

Bulgular: Toplam örneklemde her 5 ebeveynden 1 'i çocuklarıla oyun oynamıyordu, kurumlar arası fark yoktu ( $p=0.063)$ ancak oynamayanlar DH' de (\% 25.7) en fazlaydı. Oyun oynamama düșük sosyoekonomik durumla ilișkiliydi ( $\mathrm{p}=0.020)$. Ebeveynlerin \% 46.3'ü çocuklarına kitap okumuyordu, kurumlar arası fark vardır ( $\mathrm{p}=0.021)$, okumayanlar ÜH'de (\% 52.6) en fazlaydı. Yaşla kitap okuma oranları artmaktaydı $(p=0.000)$, ortanca başlangıç yaşı 23 aydı. Kitap okumamayı etkileyen faktörler çocuk yașı, anne yaşı ve sosyoekonomik durumdu $(p<0.05)$. Çocuğun ekran izlediği ortalama süre 2.64 saatti ve kurumlar arası fark vardı $(\mathrm{p}=0.000)$, süre $\mathrm{DH}$ ' de (3.22 saat) en fazlaydı. Ekran izleme süresi 36 aydan sonra belirgin artmaktaydı $(p=0.000)$.

Sonuç: Birlikte oyun oynamama DH' de, düzenli kitap okumama ÜH' de, ekran izleme süresi DH' de daha fazlaydı. Çocuk hekimlerinin görev yaptığı 2. ve 3. basamak sağlık kuruluşlarına başvuran aile ve çocukların gelișimsel olarak daha fazla desteğe ve yönlendirmeye intiyacı olduğu bulundu. Sağllk hizmetinin seviyesine göre müdahalelerin planlanması gerektiği söylenebilir.

Anahtar Sözcükler: Aile, Çocuk gelişimi, Ekran izleme, Kitap okuma, Oyun oynama ABSTRACT

Objective: The health system is the only way to access all young children and pediatric care providers are in the key position. Currently playing, reading and screen viewing habits are known as fundamental issues that affect child development however, there is insufficient data relating these issues in our country. We aimed to evaluate playing, reading and screen viewing habits of parents and how these habits are separated at different levels of health centers.

Material and Methods: A total of 451 parents (156 from third level - University Hospital-UH, 148 secondary level state hospital-SH and 147 from family health centers) attending a medical appointment for their 1-6 years old children in an 
outpatient clinic from January 2015 to January 2016 were given a questionnaire including socio-demographic data and the habits of families relating playing and reading and screen viewing.

Results: One out of 5 parents didn't play with their children, there wasn't a difference between centers however, this rate was higher in $\mathrm{SH}(25.7 \%)$. Playing not with the child was related to low socioeconomic status ( $\mathrm{p}=0,020)$. In total $46.3 \%$ of parents didn't read to their child, this rate was highest in UH (52.6\%). The frequency of reading was increased with age, the median age to start reading was the age of 23 months. Factors relating not reading were child age, maternal age and socioeconomic status. Mean screen time of children was 2.64 hours and, it was highest in $\mathrm{SH}$ (3.22 hours). Screen time was increased significantly after the age of 36 months ( $p=0.000)$.

Conclusion: It was found that the families and children who applied to secondary and third level Health centers where pediatricians worked were more need to be supported and guided. İnterventions should be planned according to the level of health services.

Key Words: Family, Child development, Screen viewing, Reading book, Playing

\section{GiRiş}

Gelişimin erken yılları öğrenme yeterliliği ve davranış becerileri ile ömür boyu sağlık ve iyilik haline öncülük etmektedir. Sağlık sistemi ise bütün küçük çocuklara sosyoekonomik durumdan bağımsız olarak erişebilmenin tek yoludur. Bu sebeple yüksek gelirli ülkeler sağlık sistemlerini gelişimsel zorlukları önlemek, belirlemek ve erken müdahale etmek üzere yeniden gözden geçirmişlerdir. Yakın zamanda düşük ve orta gelirli ülkelerde de sağlık sisteminin bütün çocuklara ulaşllabilirliğini sağlamak için bir çaba başlatılmıştır $(1,2)$. Yüksek kalitede ve gelişimsel konulara yer verilen bir sağlık sisteminin her çocuk için ulaşılabilir olmasını sağlamak için yerel, ulusal ve uluslararası düzeyde düzenlemeler gerekmektedir (3). Çocuk sağlığı hizmeti verenler, ailelere ulaşabilmek ve bu sayede küçük çocukların gelişimsel ve davranışsal potansiyel risklerini belirlemek ve önlemek için anahtar konumdadırlar. Düzenli çocuk sağlığı hizmeti veren aile hekimlerinden başka, çocuk doktorları da çocuğun sadece tıbbi sorunlarından değil gelişimsel ve sosyal bağlamda da iyilik halinden sorumludurlar (4). Ailelerin çocuklarının gelişimsel durumu hakkındaki endişelerine yer vermek ya da yaşa uygun gelişimi destekleyici aktiviteler ile ilgili kanıta dayalı ve doğru bilgi vermek her basamaktaki sağlık kuruluşunda görevli çocuk sağlığı hizmeti verenlerin temel görevlerinden biri olmalıdır $(5,6)$. Çocuk gelişimi ile ilgili yaşa uygun bilgiye sahip olmanın etkin ebeveynlik yetileri ve dolayısıyla daha iyi çocukluk çağı sonuçları ile ilişkili olduğu bilinmektedir (6). Günümüzde oyun, okuma ve ekran izleme alışkanlıkları çocukların gelişimini etkileyen en temel konular olarak bilinmektedir. Anne, babaların çocukları ile birlikte zaman geçirerek yaşa uygun oyun oynaması çocuğun sağlıklı fiziksel ve ruhsal gelişimi ve genel iyilik hali için son derece gereklidir. Oyunda aktif bir katılımcı olmak sadece bilişsel gelişimi desteklemek için değil çocuğun duygu ve düşüncelerini ifade etmesine, deneyimlerini anlamlandırmasına, uyum ve baş etme becerilerini öğrenmesine ve geliştirmesine yardımcı olmak açısından da önemlidir. Okul öncesi dönemdeki bir çocuğun duygu ve davranışlarını düzenleyerek geliştirebilmesi için beraber yaşa uygun oynamanın önemi büyüktür (7). Diğer bir alışkanlık olarak çocuğa kitap okuma ebeveyn-çocuk ilişkisini güçlendiren, sosyal-duygusal, bilişsel ve dil gelişimine katkıda bulunan bir faktör olup, çocuğa zengin dil ortamının sunulduğu en etkili yollardan biridir. Daha sonraki okuma başarısı ile ilişkili olarak epigenetik bir faktör olabileceği de bildirilmiştir (8). Ekran maruziyeti ise günümüzde sıkça tartışılan bir konu olup zaman zaman aileler tarafından destekleyici bir araç olarak da kullanılmak istenebilmektedir. Bu noktada ekran kullanımının kaç yaşından sonra ve nasıl olması gerektiği konusundaki bilginin sağlık personeli tarafından her fırsatta aktarıması gerekmektedir (8). Çocuk gelişimini etkileyen temel ebeveyn alışkanlıklarına dair ülkemizde yeterli veri olmadığı için sağlık sisteminin farklı düzeylerinde değerlendirmek yeni politika ve müdahaleler geliştirilebilmesi açısından önemlidir. Bu çalışmada ebeveynlerin çocuklarının gelișimini etkileyen oyun oynama, kitap okuma ve ekran izletme alışkanlıklarını değerlendirmeyi ve bu alışkanlıkların sağlık sisteminin her düzeyinde nasıl ayrıştığını araştırmayı amaçladık.

\section{GEREÇ ve YÖNTEMLER}

Bu çalışma Gelişimsel Pediatri Bilim Dalı tarafından Hacettepe Üniversitesi Tıp Fakültesinde etik kurul onayı alındıktan sonra yürütülmüştür. Ocak 2015' ten Ocak 2016' ya kadar 1-6 yaş arasındaki çocuklarına yönelik tıbbi bir hizmet için bașvuran toplam 451 ebeveyne (156' sı üçüncü basamak sağlık merkezi-Üniversite Hastanesi-ÜH, 148'i ikinci basamak sağlık merkezi-Devlet Hastanesi-DH ve 147 si birinci basamak sağlık merkezi- Aile Sağlığı Merkezi-ASM) bir anket verildi. Bu ankette sosyodemografik bilgilerin yanında ebeveynlerin çocukları ile oyun oynama, çocuklarına kitap okuma ve çocukların ekran izleme alışkanlıkları değerlendirildi. Çalışma ekibi tarafından on üç soru ile hazırlanan anket formunu aileler kendileri okuyarak 2 dakika içinde cevaplandırdı. "Çocuğunuzun gelişimini desteklemek için onunla yaşına uygun oyunları (bebekler, arabalar, evcilik, yapboz, saklambaç gibi) birlikte oynuyor musunuz? Çocuğunuza her gün kitap okuyor musunuz? Eğer çocuğunuza kitap okuyorsanız ne zaman başladınız? Çocuğunuz günde toplam kaç saat ekran başında (TV, bilgisayar, tablet, telefon gibi cihazlarla) zaman geçirir?" ailelere yöneltilen temel sorulardı. Örneklem akut ya da kronik sağlık sorunu ile ayaktan sağlık hizmetine başvuran hastalar arasından rastgele seçildi. Araştırmayı kabul eden anne ya da babaya doldurmaları için anket formları verildi. 
Katılımcıların sosyoekonomik durumları (SED) her iki ebeveynin mezuniyet ve mesleki durumunu temel alan Hollingshead Redlich ölçeği ile değerlendirildi (9). Sosyoekonomik sosyokültürel düzeyi genellemek için kullanılan bu ölçümde, anne-babanın iş ve eğitim durumu 1-5 arasında skorlanır. Yüksek Hollingshead Redlich ölçeği skorları düşük SED anlamındadır.

İstatistik analizler SPSS 21 software ile yapılmıştır. Tanımlayıcı analizler ve verilerin dağlım özelliklerine göre bivariate (ki-kare, bağımsız gruplar $T$ testi ve Mann Whitney) karşılaştırmalar yapılmış ve $p<0.05$ anlamlı olarak kabul edilmiştir. Annebabaların çocukları ile oyun oynama, kitap okuma ve ekran izletme alışkanlıkları çocuk yaşı ve cinsiyeti, anne yaşı ve eğitimi, SED ve başvurduğu kurum açısından ikili analizlerle ayrı ayrı değerlendirilmiş; $p<0.2$ olan değişkenler lojistik regresyon analizi, enter methodu ile çoklu analize dahil edilmiştir.

\section{BULGULAR}

Katılımcıların 156'sı üçüncü basamak sağlık merkezi - ÜH' den, 148'i ikinci basamak sağllk merkezi - DH' den ve 147'si birinci basamak sağlık merkezi - ASM' lerden olmak üzere 451 ebeveyn ve çocuktan oluşmaktaydı. Çocukların ortanca yaşı 37 ay (12-72 ay)'di. Yüzde kırk dokuzu kız (ortanca yaş 36 ay) ve $\% 51$ ' i erkekti (ortanca yaş 41 ay). Cinsiyetler arası yaş farkı yoktu ( $p=0.58$ ). Soru forumunu dolduranların çoğunluğu anneydi (\%82). Bütün katılımcılar Türkçe konuşuyor ve Ankara ilinde yaşıyorlardı. Sosyoekonomik durum açısından sağlık kuruluşları arasında fark vardı $(p=0.000)$. Detaylı sosyodemografik veriler Tablo l' de verilmiştir.
Toplam örneklemde ebeveynlerin \% 80.2' si çocuklarılyla yaşına uygun bir şekilde oyun oynadıklarını bildirmiştir. Bu kapalı uçlu sorunun evet ve hayır şeklindeki cevap seçenekleri annenin öz değerlendirmesiydi. Buna göre 89 ebeveyn (\%19.7) çocuklarıla yaşına uygun bir şekilde oynamadıklarını belirtmiştir. Yaklaşık her 5 ebeveynden 1 'i çocuklarıla oynamıyordu. Kurumlar arası istatiksel olarak fark olmamakla birlikte $(p=0.063)$ bu sıklık DH' de \% 25.7 ile en yüksekti (4 ebeveynden 1'i). Düzenli oyun oynama alışkanlığının düşük SED' e sahip ailelerde daha az olduğu ( $p=0.020$ ) bulundu. İili analizlerde oyun oynamayı etkileyen ve $p<0.2$ olan başka faktör bulunamadı.

Ebeveynlerin yaklaşık yarısı (\% 46.3) çocuklarına düzenli (her gün) kitap okumuyordu ve kurumlar arası anlamlı fark vardır $(p=0.021)$. ÜH' de ebeveynlerin \% 52.6' ü çocuklarına kitap okumuyordu, bu oran ASM ve DH' de sırasılyla \% 49' u ve \% 37.2'di. Yaş arttıkça kitap okuma yüzdeleri artmaktaydı ( $p=$ 0.000). Çocuk $12-23$ aylıkken kitap okuma sıklı̆ı \%36.7 iken, 60-72 ayda \%69.5'di. Kitap okumaya başlama yaşı 0-70 ay arasında değişmekle birlikte ortanca başlangıç yaşı 23 aydı. Ayrıca çocuğa her gün kitap okuma alışkanlı̆̆ının anne yaşı $(p=0.001)$ ve SED düştükçe $(p=0,000)$ azaldığı bulundu. İkili analizlerde kitap okumamayı etkileyen faktörler olarak $p<0.2$ olan değişkenler; cinsiyet, başvurduğu kurum, anne ve çocuk yaşı ve Hollingshead Redlich ölçeği skoru (yüksekliği düşük SED'i gösterir) lojistik regresyon analizi ile değerlendirildiğinde çocuk yaşı (OR: 0.97, Cl:0.96-0.99), anne yaşı (OR: 0.95, Cl:0.91-0.99) ve Hollingshead Redlich ölçeği skoru (OR: 1.82, Cl:1.47-2.25) başvurduğu kurum ve cinsiyetten bağımsız olarak anlamlı bulundu.

Tablo I: Katılımcıların sosyodemografik özellikleri.

\begin{tabular}{|c|c|c|c|c|}
\hline & $\begin{array}{c}\text { ÜH } \\
(\mathrm{N}=156)\end{array}$ & $\begin{array}{c}\mathrm{DH} \\
(\mathrm{N}=148)\end{array}$ & $\begin{array}{c}\text { ASM } \\
(\mathrm{N}=147)\end{array}$ & $\mathbf{p}$ \\
\hline Çocuk yaş (ortalama). (SD)(ay) & $38.3 \pm 18.1$ & $46.2 \pm 17.8$ & $35.3 \pm 15.4$ & 0.000 \\
\hline Cinsiyet (kız) n(\%) & 69 (44.2) & $84(56.8)$ & $68(46.2)$ & 0.066 \\
\hline Anne yaş (ortalama). (SD)(yıl) & $30.1 \pm 5.01$ & $30.6 \pm 4.56$ & $30.3 \pm 5.7$ & 0.474 \\
\hline $\begin{array}{l}\text { Anne eğitim n(\%) } \\
\text { IIlkokul } \\
\text { Ortaokul } \\
\text { Lise } \\
\text { Üniversite }\end{array}$ & $\begin{array}{l}54(34.6) \\
19(12.1) \\
50(32.0) \\
33(21.1)\end{array}$ & $\begin{array}{l}19(12.8) \\
27(18.2) \\
63(42.5) \\
39(26.3)\end{array}$ & $\begin{array}{l}54(36.7) \\
43(29.2) \\
33(22.4) \\
17(11.5)\end{array}$ & $\begin{array}{l}0.545 \\
0.050 \\
0.900 \\
0.173\end{array}$ \\
\hline Anne meslek (çalışır) n(\%) & $36(23.0)$ & $65(43.9)$ & $17(11.5)$ & 0.000 \\
\hline Baba yaş (ortalama). (SD)(yıl) & $34.3 \pm 5.5$ & $34.2 \pm 4.5$ & $34.4 \pm 5.9$ & 0.814 \\
\hline $\begin{array}{l}\text { Baba eğitim n(\%) } \\
\text { Illkokul } \\
\text { Ortaokul } \\
\text { Lise } \\
\text { Üniversite }\end{array}$ & $\begin{array}{l}33(21.1) \\
26(16.6) \\
52(33.3) \\
45(28.8)\end{array}$ & $\begin{array}{l}17(11.4) \\
17(11.4) \\
65(43.9) \\
49(33.1)\end{array}$ & $\begin{array}{l}54(36.7) \\
32(21.7) \\
38(25.8) \\
23(15.6)\end{array}$ & $\begin{array}{l}0.002 \\
0.006 \\
0.001 \\
0.006\end{array}$ \\
\hline Baba meslek (çalışır) $N(\%)$ & $117(75.0)$ & $108(72.9)$ & $125(85.0)$ & 0.350 \\
\hline Evlilik durumu (evli) N(\%) & $152(97.4)$ & $143(96.6)$ & $141(95.9)$ & 0.398 \\
\hline SED*(ortalama)(SD)(aralık) & $3.25 \pm 1.09$ & $2.92 \pm 0.87$ & $3.69 \pm 1.03$ & 0.000 \\
\hline
\end{tabular}

ÜH: Üniversite hastanesi, DH: Devlet Hastanesi, ASM: Aile Sağlığı Merkezleri, SED: Sosyoekonomik durum *:Hollingshead Redlich ölçeği 
Tablo II: Sağlık kuruluşlarının seviyesine göre ebeveynlerin çocukları ile birlikte oyun oynama, kitap okuma yüzdeleri ve çocukların ekran izleme süreleri.

\begin{tabular}{|c|c|c|c|c|}
\hline$n(\%)$ & $\begin{array}{c}\text { ÜH } \\
\mathrm{N}=156\end{array}$ & $\begin{array}{c}\text { DH } \\
\mathrm{N}=148\end{array}$ & $\begin{array}{c}\text { ASM } \\
\mathrm{N}=147\end{array}$ & $\mathbf{p}$ \\
\hline Birlikte oyun oynama & $133(85.2)$ & $110(74.3)$ & $119(80.9)$ & 0.063 \\
\hline Birlikte kitap okuma & $74(47.4)$ & $93(62.8)$ & $75(51.0)$ & 0.021 \\
\hline $\begin{array}{l}\text { Çocukların ortalama ekran izleme } \\
\text { süresi (saat } \pm \text { SD) }\end{array}$ & $2.51 \pm 2.9$ & $3.22 \pm 2.5$ & $2.19 \pm 2.1$ & 0.000 \\
\hline
\end{tabular}

ÜH: Üniversite hastanesi, DH: Devlet Hastanesi, ASM: Aile Sağlığı Merkezleri, SED: Sosyoekonomik durum

Tablo III: Yaşlara göre ebeveynlerin kitap okuma yüzdeleri ve ekran izletme süreleri.

\begin{tabular}{c|c|c}
\hline Ay* & Kitap Okuma (\%) & $\begin{array}{c}\text { Ekran izletme süreleri } \\
\text { Ortanca saat(aralık) }\end{array}$ \\
\hline $12-23$ & $30(36.7)$ & $0.5(0-10)$ \\
\hline $24-35$ & $40(42.1)$ & $1(0-10)$ \\
$36-47$ & $53(61.6)$ & $2(0-12)$ \\
$48-59$ & $53(58.9)$ & $3(0-14)$ \\
$60-72$ & $66(69.5)$ & $3(0-14)$ \\
\hline
\end{tabular}

*Yaş arttıkça kitap okuma sıkığı ve ekran izletme süresi artmaktaydı $(p=0.000)$.

Çocuğun ekran izlemesine izin verilen süre 0 ile 14 saat arasında değişmekteydi, ortalama $2.64 \pm 2.59$ saatti ve sağllık merkezleri arasında fark vardı $(p=0.000)$. Ortalama $3.22 \pm 2.5$ saat ile DH' de ekran izleme süresi en fazlaydı. Yaşlara göre ortalama ekran izleme sürelerinde 36 aylıktan sonra belirgin bir artış vardı $(p=0.000)$. Toplam örneklem grubumuzda 2 yaş altı çocuklar için ekran izleme süresi ortalama $1.47 \pm 2.1$ iken, 2 yaş üstü çocuklar için $3.08 \pm 2.6$ saatti. İkili analizlerde ekran izletmeyi etkileyen ve $p<0.2$ olan başka faktör bulunamadı.

Sağlık kuruluşlarının seviyesine göre ebeveynlerin çocukları ile oyun oynama, kitap okuma yüzdeleri ve çocukların ekran izleme süreleri Tablo Il' de ayrıntılı olarak verilmiştir. Yaşlara göre ebeveynlerin kitap okuma ve ekran izletme alışkanlıkları ise Tablo III' de verilmiştir.

\section{TARTIŞMA}

Çocuk sağlığı hizmeti için farklı basamaklardaki sağlık kuruluşlarına başvuran ebeveynlere çocuk gelişimini etkileyen oyun oynama, kitap okuma ve ekran izletme alışkanlıkları ilgili bilgiler sorulmuştur. Çocuğa kitap okumama yüzdesi ÜH' de ve ekran izletme süresi DH' de istatistiksel olarak daha fazlaydı. Çocuk hekimlerinin görev yaptığı 2. ve 3.basamak sağlık kuruluşlarına başvuran aile ve çocukların bu alışkanlıklar açısından daha fazla destek ve yönlendirmeye ihtiyacı olduğu bulunmuştur.

Değerlendirilen ebeveyn davranışlarından biri yaşa uygun çocukla oyun oynamaktı. Çalışmamızda yaklaşık beş ebeveynden biri çocuğu ile birlikte oyun oynamadığını belirtmiştir. Merkezler arası istatiksel olarak fark olmamakla birlikte bu oran DH' de (\%25.7) en fazlaydı. Oysaki oyun küçük çocuklar için bir çeşit iletişim yoludur, ayrıca sağlıklı sosyal-duygusal, bilişsel ve fiziksel gelişim için gereklidir. Özellikle olumsuz koşullarda yaşayan çocukların dayanıkılık ve esneklik (resilience) geliştirmesi ve ebeveynlere dünyayı onların gözünden görmek için eşsiz bir fırsat sunması açısından önemlidir (10). Bu bağlamda sağlık çalışanlarının aileleri oyunun önemi konusunda bilgilendirmesi, çocukları ile serbest-yapılandırımamış ya da yarı yapılandırımış oyunları oynamaları için teşvik etmesi, uygun ortam ve kaynaklara ulaşabilmeleri için yönlendirmesi gerekmektedir (11).

Çalışmamızdaki diğer bir sonuç ebeveynlerin çocuğa kitap okuma alışkanlığı ile ilgiliydi. Amerikan Pediatri Akademisi (APA)' nın önerdiği gibi pediatrik bakım verenler bebeklik döneminden itibaren bütün ebeveynlere çocuklarına yüksek sesle okumayı tavsiye ederek okur - yazarlık becerilerini teşvik etmelidirler. Karşılıklı etkileşim içerikli kitap okuma sadece dil becerilerine, sosyal-duygusal gelişime ve okula hazır olma durumuna katkıda bulunmayacak, aynı zamanda ebeveyn-çocuk ilişkisini de güçlendirecektir (8). Biliyoruz ki olumsuz koşullarda yaşayan çocuklar erken çocukluk çağı streslerine daha fazla maruz kalmakta ve ebeveynlerinden daha az kelime duymaktadırlar ve 3 yaşında diğer yaşıtlarına göre daha az kelime bilmektedirler. Ancak yüksek gelirli ailelerde yaşayan çocuklar dahi hızlı yaşam koşulları ya da okumanın önemine dair bilgi yetersizliği nedeniyle ebeveynleri ile dil içeriği zengin etkileşimler kuramamaktadırlar. Bu yüzden bütün aileler çocuklarına kitap okumaları yönünde teşvik edilmelidirler $(8,12,13)$. Çalışmamızda ÜH'de ebeveynlerin yarısından fazlası çocuklarına kitap okumuyordu. Genel örneklemde ebeveynlerin yaklaşık yarısı (\% 46.3) çocuklarına düzenli kitap okumuyordu ve yaş arttıkça kitap okuma oranları artmaktaydı. 2011-2012 yılları arasında Amerika Birleşik Devletleri'nde yapılmış ulusal bir araştırmada ulusal yoksulluk sınırının üstünde kalan ailelerin \%40'ının, altında kalan ailelerin \%66' sının 0-5 yaş arası çocuklarına günlük kitap okuma alışkanlıklarının olmadığı bulunmuştur (14). Bebeklik döneminden itibaren çocuğa kitap okuma tavsiye edildiği halde çalışma grubumuzda okumaya yaklaşık 2 yaşında başlanılmıştı ve bu süre okula başlama yaşına kadar da gecikmeliydi. Literatürde ülkemizde bu konuda yapılmış herhangi bir sıklık araştırmasına rastlanmamıştır ancak, çocuğun artan gelişimine 
paralel olarak ebeveynlerin okuma sıklığının arttığı bilinmektedir (15). Çalışmamızda çocuğun yaşı, anne yaşı ve SED düştükçe ailelerin çocuklarına kitap okuma alışkanlıklarının cinsiyet ve başvurduğu kurumdan bağımsız olarak azalması ise sosyodemografik açıdan risk altında olan bu grubun ne kadar destek intiyacı olduğunu bir kez daha göstermek açısından önemlidir.

Günümüzde medya maruziyeti artmış bir toplum sağlığı sorunu olarak tanımlanmıştır. Literatüre göre APA 2 yaş altında elektronik medya maruziyetini önermemekte, daha büyük çocukların da 2 saatten fazla maruz kalmasını önermemektedir (8). Bizim örneklemimizde televizyon en kolay ve genel ulașılabilir ekran türü olarak tanımlandı ve DH' de ekran izleme süresi en fazlaydı. Ortalama ekran izleme süresi 2 yaş altı için 1.47 saatti. Bu yaş grubunda dahi maksimum sürenin 12 saate kadar çıktığı görüldü. Televizyon ekranından tam ve doğru kavrama erken çocukluk döneminde oluşmaz ve bu yaș döneminde gerçek hayat deneyimlerinden daha çok öğrenirler (16,17). Ayrıca literatürde erken dönemden itibaren ekran izlemenin bilişsel, dil ve yönetici fonksiyonların gelişimine yönelik olumsuz etkileri pek çok kez gösterilmiştir (16-19). Genel örneklemde ekran izleme süresi, kitap okumada olduğu gibi, yaș ile artmaktaydı, özellikle 36 aydan sonra belirgin bir artış vardı. Bazı ebeveynler ekranı bir bakım aracı ya da çocuk gelişimini destekleyici bir araç olarak kullanabileceğinden, bütün ebeveynlere çocukları ile karşılıklı konuşma ve birebir etkileşim zamanını arttırmaları ve sağlıklı bir aile medya kullanım planı oluşturmaları yönünde tavsiye verilmelidir $(8,20)$.

Çalışmamızın kısıtııı̆ı ebeveyn alışkanlık veya davranışlarını değerlendiren standart bir ölçek kullanılmaması iken, güçlü yanı çocuk gelişimini etkileyen temel ebeveyn alışkanlıklarını sağlık sistemimizin farklı düzeylerinde değerlendiren ilk çalışma olmasıdır.

Yaşa uygun ve kanıta dayalı doğru bilgiye sahip olmanın gelişimsel sonuçlara olumlu etkisi göz önünde bulundurularak, ailelere bu konularda doğru bilgilerin her fırsatta ve sağlık hizmetinin her seviyesinde sağlanması gerekmektedir. Çocuk hekimleri karşılaștıkları engellere rağmen sağlığın her alanında çocuğun iyilik halinden sorumludurlar $(6,21,22)$.

Sonuç olarak; ailelerin çocuklarının gelişimini etkileyen temel alışkanlıklarından olan çocukları ile oyun oynama, kitap okuma ve ekran izletme alışkanlıkları sağlık sisteminin farklı seviyelerinde değerlendirildi. Birlikte oyun oynamama ve ekran izletme süresi devlet hastanesinde, düzenli kitap okumama üniversite hastanesinde daha fazlaydı. Çocuk hekimlerinin görev yaptığı 2. ve 3. basamak sağlık kuruluşlarına başvuran aile ve çocukların gelişimsel olarak daha fazla desteğe ve yönlendirmeye ihtiyacı olduğu bulundu. Bu bağlamda sağlık sistemi içinde çocukların en üst gelişim düzeyine ulaşmalarını sağlamak için sağlık hizmetinin seviyesine göre yeterli sağlık personeli sayısı ve zaman planlanması yapılması ve eğitim verilmesi gerektiği sonucuna varılabilir.

\section{KAYNAKLAR}

1. Ertem IO, Pekcici EB, Gok CG, Ozbas S, Ozcebe H, Beyazova U. Addressing early childhood development in primary health care: experience from a middle-income country. J Dev Behav Pediatr 2009; 30:319-26.

2. Grantham-McGregor S, Cheung YB, Cueto S, Glewwe P, Richter L, Strupp B. International Child Development Steering Group. Developmental potential in the first 5 years for children in developing countries. Lancet 2007;6:60-70.

3. Black MM,Walker SP,Fernald LCH,Andersen CT, DiGirolamo AM, Lu $\mathrm{C}$,et al. Early childhood development coming of age: science through the life course. Lancet 2017; 7:77-90.

4. Schor EL. The future pediatrician: promoting children's health and development. J Pediatr 2007; 151:11-6.

5. Oberklaid F, Efron D. Developmental delay-identification and management. Aust Fam Physician 2005; 34:739-42.

6. Rikhy S, Tough S, Trute B, Benzies K, Kehler H, Johnston DW. Gauging knowledge of developmental milestones among Albertan adults: a cross-sectional survey. BMC Public Health 2010; 8:18392.

7. Farley $\mathrm{Jl}$, Whipple Ee. Expanding infant mental health treatment services to at-risk preschoolers and their families through the integration of relational play therapy. Infant Ment Health J 2017; 38:669-79.

8. High PC, Klass P, Council on Early Childhood. Literacy promotion: an essential component of primary care pediatric practice. Pediatrics 2014; 134:404-9.

9. Hollingshead AB, Redlich FC. Social class and mental illness: a community study. Am J Public Health 2007; 97:1756-7.

10. Ginsburg KR; American Academy of Pediatrics Committee on Communications; American Academy of Pediatrics Committee on Psychosocial Aspects of Child and Family Health. The importance of play in promoting healthy child development and maintaining strong parent-child bonds. Pediatrics 2007; 119:182-91.

11. Milteer RM, Ginsburg KR. Council On Communications And Media Committee On Psychosocial Aspects Of Child And Family Health. The importance of play in promoting healthy child development and maintaining strong parent-child bond: focus on children in poverty. Pediatrics 2012; 129:204-13.

12. Garner AS, Shonkoff JP; Committee on Psychosocial Aspects of Child and Family Health; Committee on Early Childhood, Adoption, and Dependent Care; Section on Developmental and Behavioral Pediatrics. Early childhood adversity, toxic stress, and the role of the pediatrician: translating developmental science into lifelong health. Pediatrics 2012; 129: e224-31.

13. Brown A; Council on Communications and Media. Media use by children younger than 2 years. Pediatrics 2011; 128:1040-5.

14. Data Research Center for Child and Adolescent Health. 2011/12 National Survey of Children's Health. Available from: http://www. childhealthdata.org/ Accessed April 13, 2013

15. Tercanlı Metin G, Gökçay G. Bebeklik ve Erken Çocukluk Döneminde Kitap Okuma: Çocuk Sağlığı İlemlerinde Etkili Bir Gelişim Önerisi. Çocuk Dergisi 2014;14:89-94.

16. Anderson DR, Pempek T. Television and very young children. Am Behav Sci 2005; 48:505-22.

17. Anderson DR, Subrahmanyam K; Cognitive Impacts of Digital Media Workgroup. Digital Screen Media and Cognitive Development. Pediatrics 2017; 140:57-61. 
18. Barr R, Lauricella A, Zack E, Calvert SL. Infant and early childhood exposure to adult-directed and child-directed TV programming. Merrill-Palmer Q 2010; 56:21-48.

19. Zimmerman FJ, Christakis DA. Children's television viewing and cognitive outcomes: a longitudinal analysis of national data. Arch Pediatr Adolesc Med 2005; 159:619-25.

20. Reid Chassiakos YL, Radesky J, Christakis D, Moreno MA, Cross C. Council of Communications and Media Children and Adolescents and Digital Media. Pediatrics 2016; 138: e20162593.
21. Rhodes A, Sciberras E, Oberklaid F, South M, Davies S, Efron D. Unmet developmental, behavioral, and psychosocial needs in children attending pediatric outpatient clinics. J Dev Behav Pediatr 2012; 33:469-78.

22. Sand N, Silverstein M, Glascoe FP, Gupta VB, Tonniges TP, O'Connor KG. Pediatricians' reported practices regarding developmental screening: do guidelines work? Do they help? Pediatrics 2005; 116:174-9. 